\title{
The spectrum of heart disease among adults at the Bamenda Regional Hospital, North west Cameroon: a semi urban setting
}

\author{
Manuel Ndo Akono ${ }^{1}$, Larissa Pone Simo ${ }^{2 *} \mathbb{D}$, Valirie Ndip Agbor ${ }^{3,4}$, Sylvain Laah Njoyo ${ }^{5}$ and Dora Mbanya 2,6
}

\begin{abstract}
Objective: We sought to determine the spectrum of heart diseases among adult patients at the Bamenda Regional Hospital in the North West Region of Cameroon. This is a chart review of echocardiographic records.

Results: In total, 673 records were included in our study, of which 506 had a definite heart disease. Of the 506, 93 had mixed cardiopathies. Their ages ranged from 18 to 105 years with a median age of 64.0 (Interquartile range $=47-75$ ) years. Females accounted for a greater proportion (55.3\%) of the study population. The most common echocardiographic diagnoses were hypertensive heart disease (41.1\%), valvular heart disease (22.3\%) and cardiomyopathies (11.4\%). The prevalence of heart failure was 17.5\%, with hypertensive heart disease being the leading cause.
\end{abstract}

Keywords: Heart disease, Aetiologies, Mixed cardiopathies, Heart failure, Bamenda, Cameroon

\section{Introduction}

The exponential rise in the use of antibiotics and vaccines, and increase in cardiovascular risk factors like hypertension and diabetes owing to westernisation and urbanisation are creating a rapid shift in the epidemiological transition from communicable to non-communicable diseases (NCDs) in sub-Saharan Africa (SSA) [1]. Non-communicable diseases are the major cause of mortality worldwide and are expected to be responsible for about $69 \%$ of the global mortality rate by 2030 [2]. Cardiovascular diseases are the second most common cause of death in SSA, after the Human Immunodeficiency Virus/ Acquired Immune Deficiency Syndrome (HIV/AIDS) [3-5]. In Cameroon, NCDs are estimated to account for $31 \%$ of all deaths, $14 \%$ of which are due to cardiovascular diseases [3].

Heart failure is associated with a 360-day all-cause mortality rate of $21.9-51.9 \%$ in SSA, and is the carrefour for a greater majority of poorly diagnosed or managed heart diseases [6]. As at now, non-ischemic heart diseases

\footnotetext{
*Correspondence: ponelarissa@gmail.com

${ }^{2}$ Faculty of Health Sciences, The University of Bamenda, Bamenda, Cameroon

Full list of author information is available at the end of the article
}

are known to be the most frequent causes of heart failure in SSA, with rheumatic heart disease (RHD), hypertensive heart disease (HHD) and non-ischemic cardiomyopathies (CMO) accounting for over $75 \%$ of cases $[4,7,8]$.

In Cameroon, there is a dearth of evidence on the profile of heart diseases with a few hospital-based studies in urban, semi-urban and rural areas of the country [9-11]. These studies highlight HHD, cardiomyopathy and RHD as the leading causes of heart disease in Cameroon. In a bit to add to the body of knowledge on the subject in Cameroon and SSA, we sought to determine the pattern of heart diseases among adult patients received for echocardiography in a referral hospital in the Northwest Region of Cameroon.
Main text
Methods
Study design, duration, setting and participants
We carried out a descriptive and retrospective study of echocardiographic records of patients aged 18 years or older referred for echocardiography from July 2015 to April 2018 at the Imagery Centre of the Bamenda Regional Hospital, Bamenda. The Bamenda Regional Hospital is the main referral government-owned hospital in the Northwest Region of Cameroon, and also acts as a 
teaching hospital for the Faculty of Health Sciences of the University of Bamenda, Cameroon. Records of patients below 18 years old and repeat procedures were excluded.

\section{Data collection and sampling}

Ethical clearance and administrative authorisation were obtained prior to the study. Transthoracic bi-dimensional M mode coupled with Doppler echocardiographic examinations were performed with a HITACHI F37 echography instrument and a 4-7 Megahertz transducer. Measurements and diagnoses were based on the recommendations of the American Society of Echocardiography (ASE) [12].

Data collected included the age, gender, comorbidity(ies), left ventricular ejection fraction and echocardiographic diagnosis. Records were exhaustively included using a consecutive sampling.

\section{Data management and statistical analysis}

Data was entered into Epidata version 3.1 and analysed using SPSS version 20.0. Medians and interquartile ranges were used to summarise continuous variables, while proportions, frequencies and charts were used to describe categorical variables. Differences in proportions were compared using the Bonferroni's test. p values $<0.05$ were considered statistically significant.

\section{Results}

In total, 719 echocardiograms were performed during the study period. Forty-six records were excluded for incomplete data; and a total of 673 records were included for data analysis. Of these, 506 had a definite heart disease. Amongst those with a definite heart disease, 93 (13.9\%) had mixed cardiopathies. The ages of the participants ranged from 18 to 105 years, with a median age of 64.0 (Interquartile range $[\mathrm{IQR}]=47-75$ ) years. Females accounted for $55.3 \%$ of the study population. The most common comorbidity was hypertension $(51.7 \%)$ followed by stroke (4.9\%) and HIV (2.5\%).

Valvular heart disease was the major cause of heart disease among young adults $<30$ years 10 (18.9\%), while HHD was consistently the commonest cause of heart diseases among participants who were 30-years and old. Also, there was an increasing trend of mixed heart disease increases with age (Table 1).

Of the 506 echocardiographic records with a heart disease, a total of 615 individual cases of heart diseases were identified (including mixed heart diseases). Hypertensive heart disease (41.1\%), VHD (22.3\%) and CMO (11.4\%) were the commonest heart diseases identified. Ischaemic heart disease was rare (7.0\%), Table 2. Males were more than twice as likely to have an ischaemic heart disease compared to their female counterparts (10.4\% versus $3.8 \% ; \mathrm{p}<0.001)$, and vice versa for pericardial diseases (9.8\% versus $6.1 \% ; \mathrm{p}=0.046)$, Table 2 .

Heart failure with reduced ejection fraction (HFrEF) occurred in 118 (17.5\%) patients, the Median age was $=65.0$ years, with patients aged over 70 years bearing the greatest burden and slightly over half of the heart failure cases occurring in males 63 (53.4\%). Hypertensive heart disease was the leading cause Fig. 1.

\section{Discussion}

We sought to describe the profile of heart diseases among adult patients referred for echocardiography in a semiurban setting of Cameroon. Hypertension accounted for over half of the comorbidity among these patients.

Table 1 Echocardiographic diagnosis by age group, Bamenda Regional Hospital, July 2015 to April 2018

\begin{tabular}{|c|c|c|c|c|c|c|c|c|}
\hline \multirow[t]{2}{*}{ Diagnosis } & \multicolumn{8}{|c|}{ Age groups (in years) } \\
\hline & $\begin{array}{l}{[<30]} \\
N(\%)\end{array}$ & $\begin{array}{l}{[30-39]} \\
N(\%)\end{array}$ & $\begin{array}{l}\text { [40-49] } \\
\mathrm{N}(\%)\end{array}$ & $\begin{array}{l}\text { [50-59] } \\
\mathrm{N}(\%)\end{array}$ & $\begin{array}{l}\text { [60-69] } \\
\mathrm{N}(\%)\end{array}$ & $\begin{array}{l}\text { [70-79] } \\
\mathrm{N}(\%)\end{array}$ & $\begin{array}{l}{[\geq 80]} \\
N(\%)\end{array}$ & $\begin{array}{l}\text { Total (\%) } \\
\mathrm{N}=673\end{array}$ \\
\hline Hypertensive HD & $3(5.7)$ & $7(12.3)$ & $22(29.7)$ & $28(28.0)$ & $44(33.6)$ & $61(37.2)$ & $27(29.3)$ & $192(28.5)$ \\
\hline Cor Pulmonale & $1(1.9)$ & $5(8.8)$ & $6(8.1)$ & $2(2.0)$ & $8(6.1)$ & $10(6.1)$ & $4(4.3)$ & $36(5.3)$ \\
\hline Cardiomyopathy & $3(5.7)$ & $4(7.0)$ & $0(0.0)$ & $8(8.0)$ & $12(9.2)$ & $12(7.3)$ & $7(7.6)$ & $46(6.8)$ \\
\hline Valvular HD & $10(18.9)$ & $6(10.4)$ & $10(13.5)$ & $10(10.0)$ & $12(9.2)$ & $16(9.8)$ & $15(16.3)$ & $79(11.7)$ \\
\hline Congenital HD & $1(1.9)$ & $0(0.0)$ & $0(0.0)$ & $0(0.0)$ & $0(0.0)$ & $0(0.0)$ & $0(0.0)$ & $1(0.2)$ \\
\hline Ischaemic HD & $0(0.0)$ & $0(0.0)$ & $0(0.0)$ & $4(4.0)$ & $5(3.8)$ & $6(3.7)$ & $5(5.5)$ & $20(3.0)$ \\
\hline Pericardial Dz & $8(15.1)$ & $7(12.3)$ & $4(5.4)$ & $3(3.0)$ & $1(0.8)$ & $3(1.8)$ & $2(2.2)$ & $28(4.2)$ \\
\hline Mixed HD & $5(9.4)$ & $7(12.3)$ & $6(8.1)$ & $14(14.0)$ & $19(14.5)$ & $21(12.8)$ & $21(22.8)$ & 93 (13.9) \\
\hline Others & $0(0.0)$ & $1(1.8)$ & $1(1.4)$ & $3(3.0)$ & $2(1.5)$ & $1(0.6)$ & $1(1.1)$ & $11(1.6)$ \\
\hline Normal exam & $22(41.5)$ & $20(35.1)$ & 25 (33.8) & $28(28.0)$ & $28(21.3)$ & $34(20.7)$ & $10(10.9)$ & $167(24.8)$ \\
\hline Total & $53(100)$ & $57(100)$ & $74(100)$ & $100(100)$ & $131(100)$ & $164(100)$ & $92(100)$ & $673(100)$ \\
\hline
\end{tabular}

$N$ frequency, $H D$ heart disease, $D z$ diseases 
Table 2 Proportion of different heart diseases (excluding normal cases)

\begin{tabular}{|c|c|c|c|c|c|c|c|}
\hline \multirow[t]{2}{*}{ Diagnosis } & \multicolumn{2}{|c|}{ Total $(\mathrm{N}=615)$} & \multicolumn{2}{|c|}{ Male $(\mathrm{N}=298)$} & \multicolumn{2}{|c|}{ Female $(\mathrm{N}=317)$} & \multirow[t]{2}{*}{$p$-value } \\
\hline & Frequency & Percentage & Frequency & Percentage & Frequency & Percentage & \\
\hline Hypertensive HD & 253 & 41.1 & 122 & 40.9 & 131 & 41.3 & 0.200 \\
\hline Ischaemic heart disease & 43 & 7.0 & 31 & 10.4 & 12 & 3.8 & $<0.001^{*}$ \\
\hline Cor Pulmonale (CP) & 51 & 8.3 & 23 & 7.7 & 28 & 8.8 & 0.973 \\
\hline Acute CP & 13 & 25.5 & 5 & 21.8 & 8 & 28.6 & \\
\hline Chronic CP & 20 & 39.2 & 9 & 39.1 & 11 & 39.3 & \\
\hline Primary Pulmonary Hypertension & 18 & 35.3 & 9 & 39.1 & 9 & 32.1 & \\
\hline Cardiomyopathy & 70 & 11.4 & 39 & 13.1 & 31 & 9.8 & 0.054 \\
\hline Hypertrophic & 15 & 21.4 & 6 & 15.4 & 9 & 29.0 & \\
\hline Dilated & 54 & 77.2 & 33 & 84.6 & 21 & 67.7 & \\
\hline Myocarditis & 1 & 1.4 & 0 & 0 & 1 & 3.3 & \\
\hline Valvular heart disease & 137 & 22.3 & 57 & 19.2 & 80 & 25.2 & 0.389 \\
\hline Rheumatic heart disease & 8 & 5.8 & 1 & 1.8 & 7 & 8.8 & \\
\hline Aortic insufficiency & 28 & 20.4 & 19 & 33.3 & 9 & 11.3 & \\
\hline Aortic stenosis & 22 & 16.1 & 10 & 17.5 & 12 & 15.0 & \\
\hline Mitral insufficiency & 63 & 46.0 & 19 & 33.3 & 44 & 55.0 & \\
\hline Mitral stenosis & 2 & 1.5 & 1 & 1.8 & 1 & 1.2 & \\
\hline Pulmonary insufficiency & 1 & 0.7 & 0 & & 1 & 1.2 & \\
\hline Pulmonary stenosis & 1 & 0.7 & 1 & 1.8 & 0 & 0.0 & \\
\hline Polyvalvulopathy & 12 & 8.8 & 6 & 10.5 & 6 & 7.5 & \\
\hline Congenital HD & 1 & 0.2 & 1 & 0.3 & 0 & 0.0 & - \\
\hline Sinus venosus & 1 & 100.0 & 1 & 100.0 & 0 & 0.0 & \\
\hline Pericardial Disease & 49 & 8.0 & 18 & 6.1 & 31 & 9.8 & $0.046^{*}$ \\
\hline Pericarditis & 18 & 36.7 & 8 & 44.4 & 10 & 32.3 & \\
\hline Effusive pericariditis & 30 & 61.3 & 10 & 55.5 & 21 & 67.7 & \\
\hline Constrictive & 1 & 2.0 & 1 & 0.1 & 0 & 0.0 & \\
\hline Others & 11 & 1.8 & 7 & 2.3 & 4 & 1.3 & 0.066 \\
\hline Aortic aneurysm & 8 & 72.7 & 6 & 85.7 & 2 & 50.0 & \\
\hline Isolated dilatation of LA & 1 & 9.1 & 1 & 14.3 & 0 & 0.0 & \\
\hline Bi-auricular dilatation & 2 & 18.2 & 0 & 0.0 & 2 & 50.0 & \\
\hline
\end{tabular}

$H D$ heart disease, $C P$ cor pulmonale, $L A$ left atrium

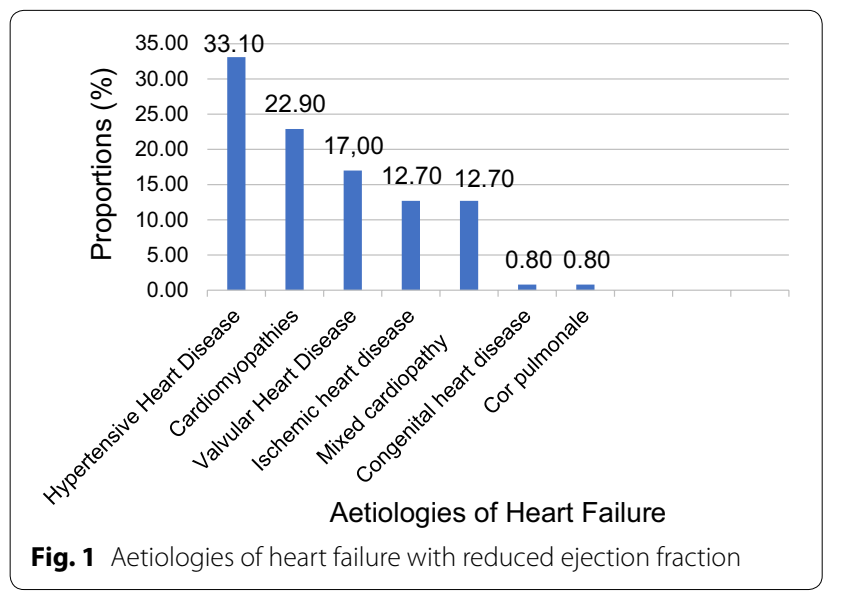

Hypertension remains a driver of cardiovascular diseases burden in SSA [5, 13, 14].

Hypertensive heart disease was the leading type of heart disease in our setting, accounting for $41.1 \%$. This is similar to findings of Tchoumi and Bureta conducted in a rural setting of the Northwest Region [11] and other semi-urban and urban settings in Cameroon $[9-11,15]$. Given the high hypertension rates in the general Cameroonian population [16], coupled with the contrastingly poor awareness, treatment and control rates [16-19], our findings were expected. Similar findings have been reported in other SSA series [7, 20,21]. However, our results differ from studies conducted in East Africa. For example, in an Ethiopia study, valvular heart disease was the commonest heart disease [22]. In addition, pericardial diseases were the main types of 
heart disease in a Malawian study [23]. This discrepancy could be due to the relatively younger population in the Ethiopian study [22]. Indeed, rheumatic heart disease which is a significant cause of VHD in SSA is a disease of children and adolescents [24]. An early diagnosis of hypertension, treatment and, most importantly, close follow up on treatment could significantly delay the occurrence of hypertensive heart disease in our setting. In addition, Of the 93 patients who presented with mixed cardiopathies, hypertensive heart disease associated mixed cardiopathies were still the most common $61(65.6 \%)$.

Valvular heart disease was the second most common type of heart disease in our setting. It accounted for $11.7 \%$ of the study population, and of these only $5.8 \%$ was secondary to rheumatic heart disease. More than half of reported cases were related to degenerative processes. Our findings are contrary to those of Jingi et al. and Nkoke et al. of the West and Southwest regions of Cameroon respectively, who reported cardiomyopathies as the second leading type of heart disease $[9,10]$. Even though rheumatic heart disease remains a major public health issue in Cameroon and SSA as a whole, it seems to be relatively scarce in our study setting. This could be explained by the fact that rheumatic heart disease occurs in a relatively young population and people aged $<30$ years represented only $8.3 \%$ of our study population. Nonetheless, $1.1 \%$ of all cases of heart disease was secondary to RHD in our study, which is relatively lower than 3.4\% reported by Jingi et al. in the West Region [10].

The relatively lower proportion of post rheumatic valvulopathies could also be explained by the fact that being a hospital-based study, cases which were not clinically evident and those who could not afford a cardiac ultrasound did not feature in the study. In addition, the fact that there are no available internationally standardised guidelines for the diagnosis of RHD in adults [25] might have contributed to an underestimation of the true prevalence of the disease in this study, especially as over $90 \%$ of our study population was at least 30 years old.

The prevalence of cardiomyopathies was $6.8 \%$, and they were the third commonest type of heart disease in our setting. Dilated cardiomyopathy remained the most common type of cardiomyopathy, accounting for $77.2 \%$ of cardiomyopathies. Our findings differ from those reported in the South West and West regions of the Cameroon $[9,10]$ in that cardiomyopathies were the third and not second most frequent type of heart disease in our setting. Though dilated cardiomyopathies were still the major types of cardiomyopathies, hypertrophic cardiomyopathies were the second most common cardiomyopathies with a proportion of $21.4 \%$.
The spectrum of pericardial disease in our study is relatively lower than that reported by Jingi et al. in West Cameroon and relatively higher than that reported by Nkoke et al. in the South West Cameroon $[9,10]$. However, findings in Malawi report pericardial diseases as the leading burden of heart disease; associating it to the coinciding HIV epidemic. The most common type of pericardial disease in our context was the pericarditis with effusion, of which $20 \%$ were associated to tuberculosis.

It is worth noting that up to $13.9 \%$ of our study population was diagnosed with more than one heart disease, what we termed mixed cardiopathies. To the best of our knowledge, this is the first study in Cameroon which reports a population with patients having more than one heart disease. This is important knowledge necessary in the diagnosis, management and prognosis of heart diseases in our context.

Heart failure occurred in $17.5 \%$ of study population, with HHD (33.1\%), CMO (22.9\%) and VHD (17\%) responsible for over $70 \%$ of the cases. Mixed cardiopathies significantly contributed to HF in our study.

The proportionately more males with heart failure in our study is similar to that reported by Kingue et al. in the General Hospital of Yaoundé, Cameroon [26]. However, there is a gender disparity between our study and findings in the Heart of Soweto study in South Africa and the Abuja Heart study in Nigeria where females formed the greater proportion of the population with heart failure $[27,28]$.

According to a recent review, HF in sub-Saharan Africa was reported as a disease of the middle-aged adult, occurring between the third and fifth decades of life, as opposed to the developed world where it is essentially a disease of the elderly, occurring in the seventh decade of life [6]. In addition, HHD, CMO and VHD were the leading causes of HF [6]. Though our findings still maintain HHD as the leading cause of heart failure in our study population, they differ from existing knowledge in that valvular heart diseases are the third commonest causes [29]. Given that hypertensive heart disease arises as a complication of longstanding systemic hypertension on the heart, with its increasing prevalence in SSA, the importance of early prevention and proper treatment of hypertension in our context cannot be over emphasized. Rheumatic heart disease instead was a rare cause of heart failure here probably accounted for by the age limit of our population. Nonetheless, mixed cardiopathies formed a sizeable proportion of the aetiologies of heart failure in our context.

\section{Conclusion}

Hypertensive heart disease is the most common heart disease in this semi-urban setting in Cameroon. A 
sizeable proportion of the population has more than one heart disease (mixed cardiopathies). Prevention of heart diseases in our setting should re-enforce awareness, mass screening, and the treatment and control of hypertension. Rendering cardiac ultrasound more available and affordable, might go a long way to improve the diagnosis, treatment and follow up of patients with heart diseases in the North West Region, and as a result, reduce the incidence of heart failure in our context.

\section{Limitation}

The retrospective design of our study gave us no control on the quality of the echocardiographic records. The diagnosis of certain cardiopathies could have been wrongly classified due the absence of records of other investigations. For example, some cases of ischaemic dilated cardiomyopathy might have been classified as non-ischemic due to absence of recorded of further investigations such as electrocardiography, stress test or coronary angiography. Furthermore, we recorded a low prevalence of rheumatic valve diseases due to difficulties of the resourceless population to get to the hospital and afford payment for echocardiography. However, with strict selection criteria, we hope this reflects to a certain degree the spectrum of heart disease among patients referred for echocardiography at the Bamenda Regional Hospital.

\section{Abbreviations \\ ASE: American Society of Echocardiography; CMO: cardiomyopathy; HF: heart failure; HFrEF: heart failure with reduced ejection fraction; IQR: interquartile range; NCDs: non-communicable diseases; RHD: rheumatic heart disease; SPSS: statistical package for social sciences; SSA: sub-Saharan Africa; VHD: valvular heart disease.}

\section{Acknowledgements}

The authors will like to acknowledge the Director of the Bamenda Regional Hospital for authorisation to carry out work in their institution, as well as the staff of this structure for their support during the study.

\section{Authors' contributions \\ Study design: LPS, VNA, DM. Drafting of study protocol: LPS, VNA, MNA, SLN, and DM. Data collection: LPS. Supervision of data collection: MNA, SLN and DM. Statistical analysis: VNA. Interpretation of results: LPS, VNA, MNA, SLN, and DM. Drafting of the initial manuscript: MNA. Revision of the manuscript: MNA, LPS, VNA, SLN, and DM. All authors read and approved the final manuscript.}

\section{Funding}

None

\section{Availability of data and materials}

The datasets for this study are available from the corresponding author on reasonable request.

\section{Ethics approval and consent to participate}

Survey of records were effectuated only after ethical approval of the study protocol by Ethical review board of the Faculty of Health Sciences, the University of Bamenda, Bamenda, Cameroon. Administrative authorisations were obtained from the Regional Delegation for Health for the Northwest Region and the Director of the Bamenda Regional Hospital, Cameroon. A pre-structured questionnaire was completed for each record and each was attributed a code for confidentiality and identification.

\section{Consent for publication}

Not applicable.

\section{Competing interests}

The authors declare that they have no competing interests.

\section{Author details}

${ }^{1}$ Bamenda Regional Hospital, Bamenda, Cameroon. ${ }^{2}$ Faculty of Health Sciences, The University of Bamenda, Bamenda, Cameroon. ${ }^{3}$ Nuffield Department of Population Health, University of Oxford, Oxford, UK. ${ }^{4}$ Department of Health Research, Health Education and Research Organization (HERO), Buea, Cameroon. ${ }^{5}$ Mozogo Sub-divisional Hospital, Mayo-Moskota, Far North Region, Mozogo, Cameroon. ${ }^{6}$ Yaoundé University Teaching Hospital (YUTH), Yaoundé, Cameroon.

Received: 23 August 2019 Accepted: 12 November 2019

Published online: 21 November 2019

\section{References}

1. Zimmet P, Alberti KGMM, Shaw J. Global and societal implications of the diabetes epidemic. Nature. 2001:13(414):782-7.

2. Mathers CD, Loncar D. Projections of global mortality and burden of disease from 2002 to 2030. PLoS Med. 2006:3(11):e442.

3. World Health Organ. Noncommunicable diseases (NCD) Country profiles. Geneva: World Health Organ; 2014.

4. Gaziano T. Global burden of cardiovascular disease. Braunwald's heart disease: a textbook of cardiovascular medicine. 8th ed. Philadelphia: Elsevier; 2007. p. 1-21

5. Gaziano TA Cardiovascular disease in the developing world and its costeffective management. Circulation. 2005;112:3547-53.

6. Agbor VN, Essouma M, Ntusi NAB, Nyaga UF, Bigna JJ, Noubiap JJ. Heart failure in sub-Saharan Africa: a contemporaneous systematic review and meta-analysis. Int J Cardiol. 2018;257:207-15.

7. Ogah OS, Adegbite GD, Akinyemi RO, Adesina JO, Alabi AA, Udofia OI, et al. Spectrum of heart diseases in a new cardiac service in Nigeria: an echocardiographic study of 1441 subjects in Abeokuta. BMC Res Notes. 2008;1:98.

8. Damasceno A, Cotter G, Dzudie A, Sliwa K, Mayosi BM. Heart failure in sub-Saharan Africa: time for action. J Am Coll Cardiol. 2007;50:1688-93.

9. Tantchou Tchoumi JC, Butera G. Profile of cardiac disease in Cameroon and impact on health care services. Cardiovasc Diagn Ther. 2013;3(4):236-43.

10. Nkoke C, Makoge C, Dzudie A, Mfeukeu LK, Luchuo EB, Menanga A, et al. A predominance of hypertensive heart disease among patients with cardiac disease in Buea, a semi-urban setting, South West Region of Cameroon. BMC Res Notes. 2017;10:684.

11. Jingi AM, Noubiap JJN, Kamdem $P$, Wawo Yonta E, Temfack E, Kouam Kouam C, et al. The spectrum of cardiac disease in the West Region of Cameroon: a hospital-based cross-sectional study. Int Arch Med. 2013;6:44.

12. Sahn DJ, DeMaria A, Kisslo J, Weyman A. Recommendations regarding quantitation in M-mode echocardiography: results of a survey of echocardiographic measurements. Circulation. 1978;58(6):1072-83.

13. Kengne AP, Awah PK, Fezeu L, Mbanya JC. The burden of high blood pressure and related risk factors in urban sub-Saharan Africa: evidences from Douala in Cameroon. Afr Health Sci. 2007:7(1):38-44.

14. Kearney PM, Whelton M, Reynolds K, Muntner P, Whelton PK, He J. Global burden of hypertension: analysis of worldwide data. Lancet. 2005;365(9455):217-23

15. Nkoke C, Menanga A, Boombhi J, Chelo D, Kingue S. A new look at acquired heart diseases in a contemporary sub-Saharan African pediatric population: the case of Yaoundé, Cameroon. Cardiovasc Diagn Ther. 2015;5:428-34

16. Kingue $S$, Ngoe CN, Menanga AP, Jingi AM, Noubiap JJN, Fesuh B, et al. Prevalence and risk factors of hypertension in urban areas of Cameroon: 
a nationwide population-based cross-sectional study. J Clin Hypertens. 2015;17(10):819-24.

17. Tianyi F, Agbor V, Njamnshi A. Prevalence, awareness, treatment, and control of hypertension in Cameroonians aged 50 years and older: a community-based study. Health Sci Rep. 2018;5:e44.

18. Dzudie A, Kengne AP, Muna WFT, Ba H, Menanga A, Kouam CK, et al. Prevalence, awareness, treatment and control of hypertension in a selfselected sub-Saharan African urban population: a cross-sectional study. BMJ Open. 2012;2(4):e001217.

19. Menanga A, Edie S, Nkoke C, Boombhi J, Musa AJ, Mfeukeu LK, et al. Factors associated with blood pressure control amongst adults with hypertension in Yaounde, Cameroon: a cross-sectional study. Cardiovasc Diagn Ther. 2016;6(5):439-45.

20. James OO, Efosa JD, Romokeme AM, Zuobemi A, Sotonye D-M. Dominance of hypertensive heart disease in a tertiary hospital in southern Nigeria: an echocardiographic study. Ethn Dis. 2012;22(2):136-9.

21. Agomuoh DI, Akpa MR, Alasia DD. Echocardiography in the University of Port Harcourt Teaching Hospital: April 2000 to March 2003. Niger J Med J Natl Assoc Resid Dr Niger. 2006;15(2):132-6.

22. Abdissa SG, Oli K, Feleke Y, Goshu DY, Begna DM, Tafese A. Spectrum of cardiovascular diseases among ethiopian patients at Tikur Anbessa specialized University Teaching Hospital. Addis Ababa. 2014;52(1):10.

23. Allain TJ, Kinley L, Tsidya B, Murray A, Cheesman M, Kampondeni S, et al. The spectrum of heart disease in adults in Malawi: a review of the literature with reference to the importance of echocardiography as a diagnostic modality. Malawi Med J. 2016;28(2):61-5.

24. Essop MR. Rheumatic and nonrheumatic valvular heart disease: epidemiology, management, and prevention in Africa. Circulation. 2005;112(23):3584-91.
25. Reményi B, Wilson N, Steer A, Ferreira B, Kado J, Kumar K, et al. World Heart Federation criteria for echocardiographic diagnosis of rheumatic heart disease — an evidence-based guideline. Nat Rev Cardiol. 2012;9(5):297-309.

26. Kingue S, Dzudie A, Menanga A, Akono M, Ouankou M, Muna W. A new look at adult chronic heart failure in Africa in the age of the Doppler echocardiography: experience of the medicine department at Yaounde General Hospital. Ann Cardiol Angeiol (Paris). 2005;54(5):276-83.

27. Sliwa K, Wilkinson D, Hansen C, Ntyintyane L, Tibazarwa K, Becker A Stewart S. Spectrum of heart disease and risk factors in a black urban population in South Africa (the Heart of Soweto Study): a cohort study. Lancet. 2008:371:915-22.

28. Ojji D, Stewart S, Ajayi S, Manmak M, Sliwa K. A predominance of hypertensive heart failure in the Abuja Heart Study cohort of urban Nigerians: a prospective clinical registry of 1515 de novo cases. Eur J Heart Fail. 2013;15(8):835-42.

29. Agbor VN, Ntusi NAB, Noubiap JJ. An overview of heart failure in lowand middle-income countries. Cardiovasc Diagn Ther. 2019. https://doi. org/10.21037/cdt.2019.08.03.

\section{Publisher's Note}

Springer Nature remains neutral with regard to jurisdictional claims in published maps and institutional affiliations.
Ready to submit your research? Choose BMC and benefit from:

- fast, convenient online submission

- thorough peer review by experienced researchers in your field

- rapid publication on acceptance

- support for research data, including large and complex data types

- gold Open Access which fosters wider collaboration and increased citations

- maximum visibility for your research: over 100M website views per year

At BMC, research is always in progress.

Learn more biomedcentral.com/submissions 